\title{
Fast Cycled Magnet demonstrator program at CERN: Instrumentation and measurement campaign
}

\author{
G. Willering, M.Bajko, F. Borgnolutti, L. Bottura, V. Datskov, G. Deferne, J. Feuvrier, L. Fiscarelli, C. Giloux, M. \\ Guinchard, V. Roger
}

\begin{abstract}
In an effort to develop economical magnets for an upgrade of the LHC injector complex, CERN started an R\&D program on superconducting Fast Cycled Magnets (FCM) in 2009. One of the challenges in this program was to develop a test station, which started working in summer 2012 when the FCM dipole demonstrator was tested. The magnet contains several important features, like forced-flow cooling of supercritical $\mathrm{He}$ and it has a protection scheme based direct voltage measurement with co-wound voltage tap wires. In this paper we report on the cryogenic and powering requirements and operation, the quench protection system, the temperature and mechanical measurements. The functioning of the test station and instrumentation are evaluated and we will discuss the measurements on a detailed level.
\end{abstract}

Index Terms-Fast Cyled Magnet, Accelerator magnet, Super Critical Helium, Dipole.

\section{INTRODUCTION}

$\mathrm{T}_{\mathrm{t} \text { a }}$ HE development of the Fast Cycled Magnet (FCM) technology was done to upgrade the PS synchrotron that is part of the LHC injector complex. After the project started in 2009, a measurement campaign on the $\mathrm{Nb}$ - $\mathrm{Ti}$ conductor technology has been done [1]. Low loss strand and cable were developed to limit AC losses during the magnet current cycle from 300 to $6000 \mathrm{~A}$ with the PS frequency of $0.4 \mathrm{~Hz}$ [2]. The 1.3-m long magnet is constructed with a room temperature iron yoke and a small cold mass consisting of two 1.3-m-long, 0.6-m-wide coils to reach a central bore field of $1.8 \mathrm{~T}$, see Fig.1.

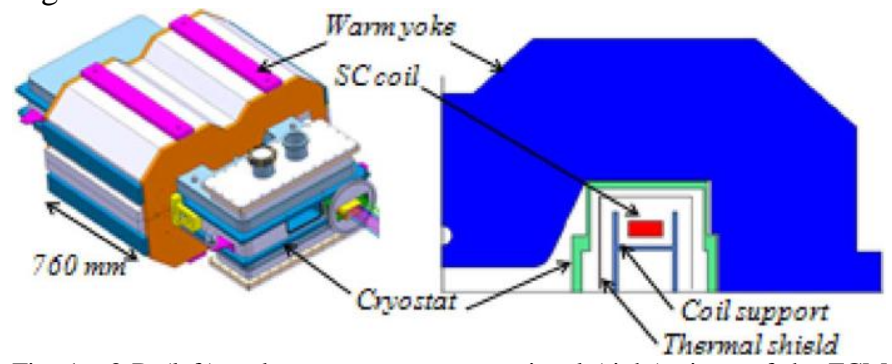

Fig. 1. 3-D (left) and one quarter cross-sectional (right) views of the FCM demonstrator magnet

Each coil consists of 10 windings of a cable made of $33 \mathrm{Nb}-\mathrm{Ti}$

Manuscript received July 17, 2013.

G. Willering is with CERN, Route de Meyrin 385, 1217 Meyrin, Suisse, (phone: +41 764879478 ; e-mail: gerard.willering@cern.ch).

M. Bajko, L. Bottura, V. Datskov, G. Deferne, J. Feuvrier, L. Fiscarelli, C. Giloux, M. Guinchard and V. Roger are with CERN.

F. Borgnolutti was at CERN and is currently with LBL. strands twisted around a central cooling pipe of $6 \mathrm{~mm}$ diameter and held in place by a tight wrap of $\mathrm{NiCr}$ wire [1], see Fig. 2. From measurements during cool-down a RRR value of 110 was deduced for the coil.

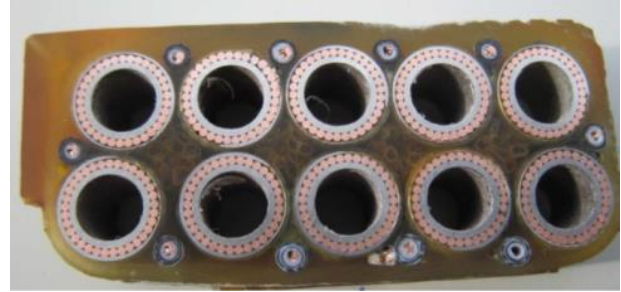

Fig 2. Cross-sectional view of the FCM dummy coil, showing the co-wound wire for quench detection, the 10 windings with a central cooling pipe and 33 strands twisted around.

All aspects of the prototype coil testing will be reported, from test station and instrumentation to quench behavior, protection, current and thermal cycling, thermal loads, mechanics, and magnetic performance.

\section{TEST PARAMETERS}

\section{A. Test station and temperature control}

In the SM18 test station at CERN a helium feedbox is developed to supply $10 \mathrm{~g} / \mathrm{s}$ of supercritical helium and gaseous helium with a temperature of 4.5 to $70 \mathrm{~K}$ at a pressure of 3 bar to the FCM magnet and to the High Temperature Superconducting link. Supercritical helium and gaseous helium are mixed to control the inlet temperature, and fed to both FCM coils. The flow and pressure were controlled for each coil separately. In addition a heater was applied on the outside of each cable at the inlet of the coil to control the temperature in each coil and to study the thermal loads in the magnet. The powering and electrical layout of the magnet is shown in Fig. 3.

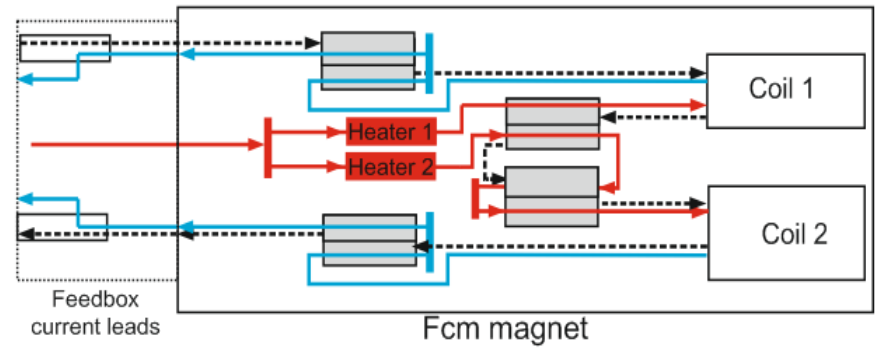

Fig. 3. Schematics of the cooling and powering circuit. The gray rectangles show the 4 interconnections, the dashed lines the path of the current and the solid lines the helium flow with in red the inlet and in blue the outlet. 
Small variations in supercritical helium supply to the feedbox in combination with a $18 \mathrm{~m}$ long, $5 \mathrm{~mm}$ diameter cooling pipe made reaching stable helium flow in the coils quite challenging. In some conditions pressure waves propagated back and forward through the coils, but in general stable settings were achieved up to $8.5 \mathrm{~K}$ by adjusting inlet and outlet pressures and flow rates.

\section{B. Instrumentation}

Inductive voltage compensation by a co-wound wire is a technique that is applied in this prototype magnet, see Fig. 2. Even with the relatively low inductance of $2.4 \mathrm{mH}$ the $6 \mathrm{kA} / \mathrm{s}$ ramp rate induces $14 \mathrm{~V}$ for the magnet. The small influence of the exact geometrical position of the coil on the magnetic field quality in the bore makes the co-winding relatively easy.

Precise thermometry by Carbon-Ceramic resistive temperature probes is performed to measure the thermal loads on the system [3]. Unfortunately the obtained precision of the enthalpy measurement of the helium was limited by the accuracy of the pressure gauges of \pm 0.05 bar, which limited the measurement accuracy of the helium enthalpy.

Each coil and superconducting joint was equipped with voltage taps for analysis of the events during quench and magnet ramping.

\section{Superconducting joints and plug}

The demountable superconducting joints were made by soldering the cable in its round shape in a copper former with a rectangular external geometry, that in turn is soldered to Rutherford cable that passes through a helium tight plug for connection with the current leads [4]. The calculated lower limit of joint resistance is $2.5 \mathrm{n} \Omega$. With a measured resistance of $2.5-4 \mathrm{n} \Omega$ the resistance added by the contact proves to be small and within specifications.

\section{QUENCH BEHAVIOR}

\section{A. Training}

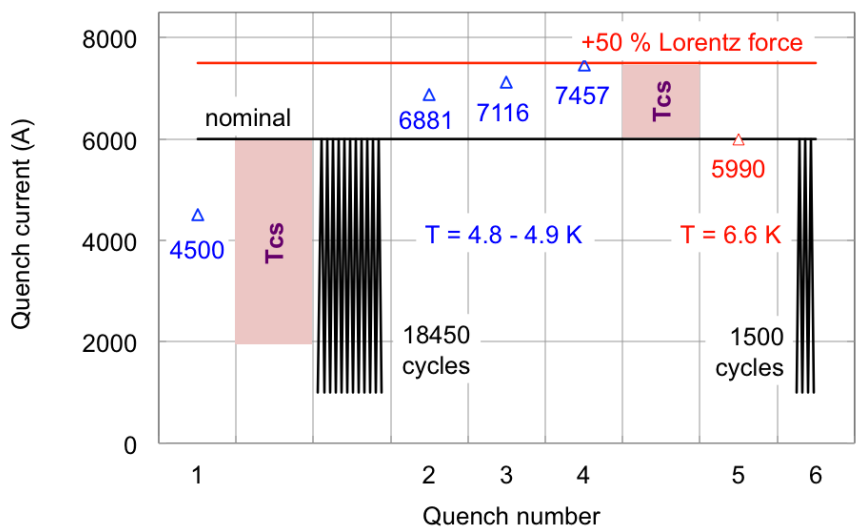

Fig. 4. Schematic representation of the test sequence with the training quenches included. $T_{c s}$ indicates the tests done at the short sample limit for variable temperatures.

Training of the magnet was performed at a temperature of $4.5 \mathrm{~K}$, where one training quench at $4.50 \mathrm{kA}$ occurred before reaching $6 \mathrm{kA}$ nominal current. After a series tests up to the short sample limit of $6 \mathrm{kA}$ at temperatures from 7 to $8.3 \mathrm{~K}$ and 18000 nominal current cycles to $6 \mathrm{kA}$ without quenching, the training was continued to $7.5 \mathrm{kA}$ with three training quenches as shown in Fig 4. After the runs up to $7.5 \mathrm{kA}$ one training quench was observed at $6 \mathrm{kA}$ at a temperature of $6.6 \mathrm{~K}$, which is $0.6 \mathrm{~K}$ below the current sharing temperature. The mechanical design of the magnet is optimized for $6 \mathrm{kA}$, but with reaching the short sample limit up to $7.5 \mathrm{kA}$, at $50 \%$ higher Lorentz forces than nominal, the magnets mechanical design has proven stable.

Due to the forced flow cooling and the energy extraction the observed recovery time is about $20 \mathrm{~s}$ at $6 \mathrm{kA}$ nominal operation. In Fig. 5 the measured inlet and outlet gas temperature profiles after a quench at $6 \mathrm{kA}$ are shown. With a quench starting in coil 2, this coil shows the highest He gas temperature up to $15 \mathrm{~K}$ within 10 seconds after the quench. In the experimental case the dump resistance of $5 \mathrm{~m} \Omega$ dissipated most of the stored energy of $43 \mathrm{~kJ}$. Integration of the enthalpy difference between inlet and outlet temperature shows that less than $1 \mathrm{~kJ}$ is dissipated in the coils.

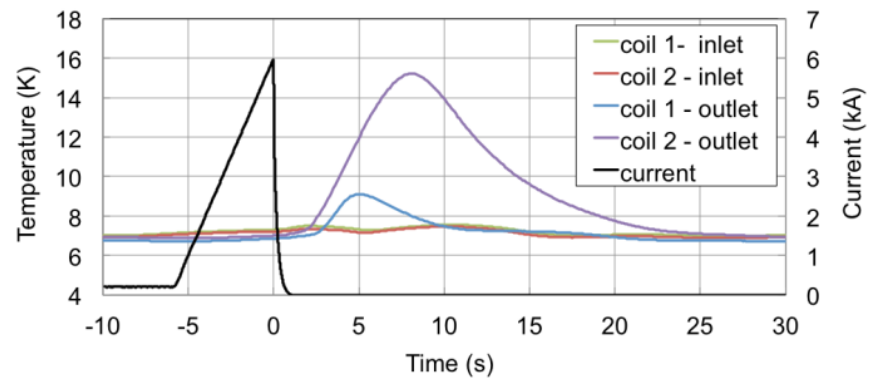

Fig. 5. Temperature profile of inlet and outlet gas temperature after a quench at $6 \mathrm{kA}$ with an initial temperature of $7 \mathrm{~K}$.

\section{B. Quench propagation}

For the five quenches recorded below the short sample limit the voltage buildup profiles up to the opening of the switch at $3 \mathrm{~ms}$ are shown in Fig. 6. The quench propagation velocity is determined at 6 to $28 \mathrm{~m} / \mathrm{s}$.

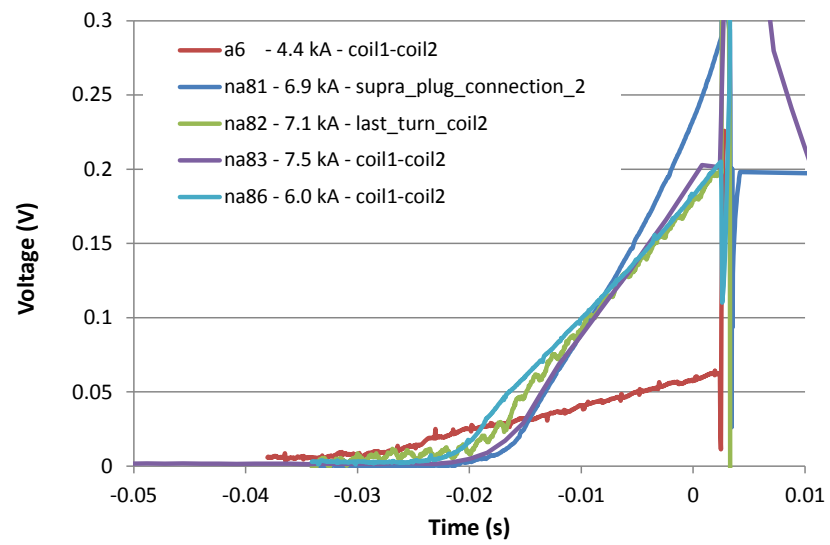

Fig. 6. Voltage buildup in the coils during the training quenches. At $\mathrm{t} \approx 3 \mathrm{~ms}$ the switch opens to enable energy extraction by the dump resistance.

\section{Short sample limit}

From the measurements on cable samples [1] the short sample limit of the coil was extrapolated with the fit for the critical surface of $\mathrm{Nb}-\mathrm{Ti}[5]$ and with a maximum field of $0.7 \mathrm{~T}$ on the coil at a current of $6 \mathrm{kA}$. The measurement sequence consisted of stabilizing the temperature after which the current ramp started. Due to a slight temperature imbalance between the 
coils, the quench typically occurred in coil 2 . To find as well the short sample limit for coil 1 the coil heater at the inlet of coil 1 was powered with $2 \mathrm{~W}$. The resulting quenches performed between 6.5 and $8.4 \mathrm{~K}$ occurred between 2 and $7.3 \mathrm{kA}$. In Fig. 7 the resulting plot is shown, where also can be seen that above $8 \mathrm{~K}$ it is mainly the interconnect region that quenches first. Due to the temperature fluctuation and the speed of the helium gas, the uncertainty in coil temperature is $\pm 0.2 \mathrm{~K}$, which corresponds to $\pm 500 \mathrm{~A}$. Within this accuracy no ramp rate dependence was found from 0.1 to $6 \mathrm{kA} / \mathrm{s}$.

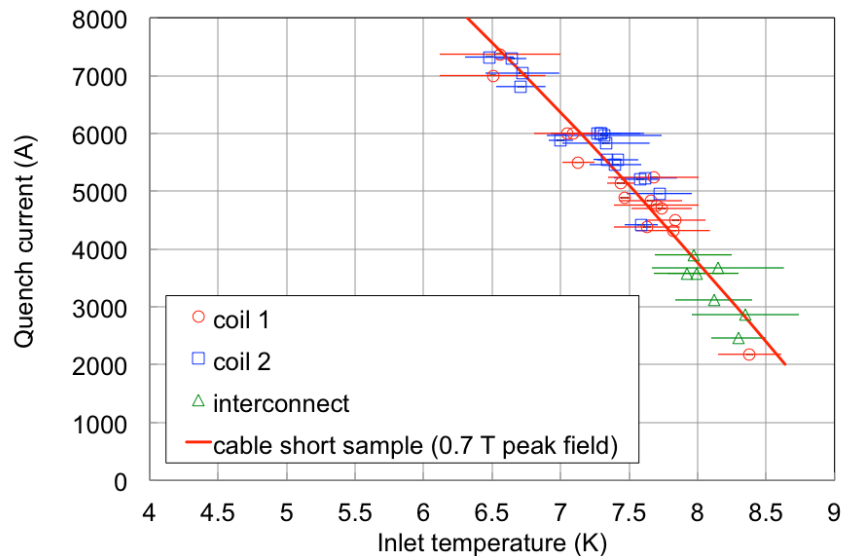

Fig. 7. Quenches at the short sample limit, with quenches in coil 1 (red), coil 2 (blue) and interconnection (green). The line is the calculated short sample of the cable.

\section{PROTECTION}

A voltage tap wire was co-wound with the coil, see Fig. 2, to compensate for the large inductive voltage at high current ramp rates of $6 \mathrm{kA} / \mathrm{s}$. A maximum of $24 \mathrm{mV}$ was measured at the highest ramp rate, which is only $0.4 \%$ of the coil voltage of $6.6 \mathrm{~V}$, see Fig. 8. With only $24 \mathrm{mV}$ of induced voltage the co-wound voltage tap technology allowed quench protection at a voltage of $100 \mathrm{mV}$ during ramp-up and ramp-down, which is sufficient for the protection.

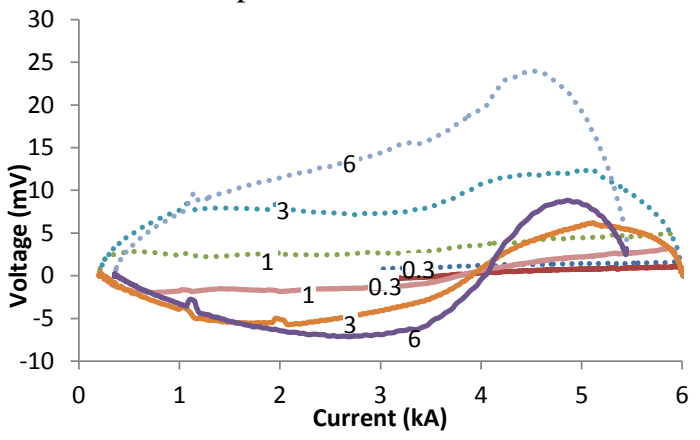

Fig. 8. Voltage measured with the compensated voltage tap for ramp rates of $0.3,1,3$ and $6 \mathrm{kA} / \mathrm{s}$. The dotted curves are for coil 2 and the dashed curves are for coil 1 .

\section{CYCLING}

\section{A. Stability}

In total 20000 cycles were performed to prove the stability of the magnet under nominal conditions. Due to limitations of the power supply a test cycle time of $3.5 \mathrm{~s}$ was applied, compared to $2.4 \mathrm{~s}$ nominal. During the longest continuous series of 4650 cycles in 5 hours at $4.5 \mathrm{~K}$ stable behavior was observed. To push the magnet to the limit, the magnet was cycled continuously 2600 times at a temperature of $6.5 \pm 0.1 \mathrm{~K}$, which is $0.5 \pm 0.1 \mathrm{~K}$ from the $T_{c s}$ limit, see Fig. 9. With the operation so close to the $T_{c s}$ the magnet proved to be very stable.

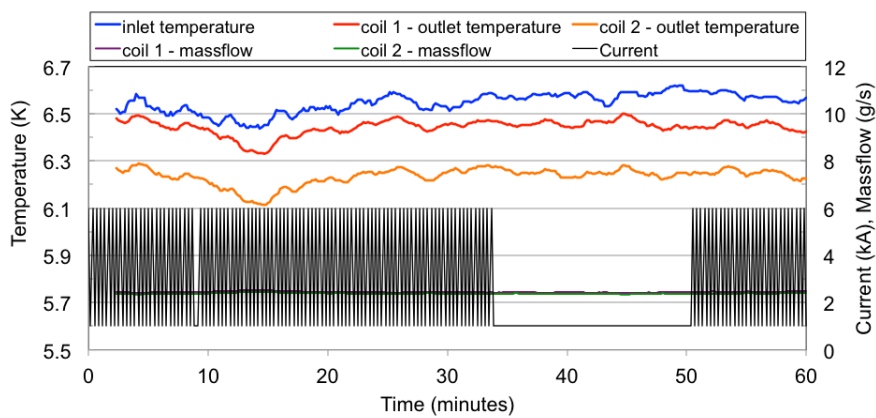

Fig. 9. Inlet and outlet temperature measurements while cycling at $0.29 \mathrm{~Hz}$. A 17 minute interval without current cycling was implemented to see possible heat load variations.

\section{B. AC loss}

By monitoring the temperatures and pressures during and after cycling the AC loss was investigated. As it is shown in Fig. 9 no significant variation in temperature can be observed when cycling stops or restarts. Due to the friction, the small diameter of the cooling tube and the flow speed of the helium of $13 \mathrm{~m} / \mathrm{s}$ a pressure drop from 1.9 to 1.2 bar over each coil is observed. With the $\mathrm{He}$ gas expanding a net drop in temperature over the coil is observed. The measured total load of the system is $0 \mathrm{~W}$ per coil, but with the limited precision in pressure measurement the enthalpy change between inlet and outlet the precision is $\pm 1 \mathrm{~W}$. The total AC loss is thus smaller than $2 \mathrm{~W}$, which is compatible with the predicted $1.2 \mathrm{~W} / \mathrm{m}$ [4].

\section{MAGNET MECHANICS}

The magnet is optimized for low loss; therefore the support structure is relatively small. In the short side of the coil, insulation is placed to prevent eddy current buildup through the support structure. Measurements with 8 strain gauges on the support structure and 8 gauges on the tie rods were performed during cycling and during quench. The measured strain on the support at $6 \mathrm{kA}$ nominal current ranged from 67 $75 \mu \mathrm{m} / \mathrm{m}$, which is in good agreement with the calculated strain of $75-105 \mu \mathrm{m} / \mathrm{m}$, see Fig. 10 [6]. The coil stability was excellent, even with Lorentz forces of $50 \%$ higher than nominal at a current of $7.5 \mathrm{kA}$.

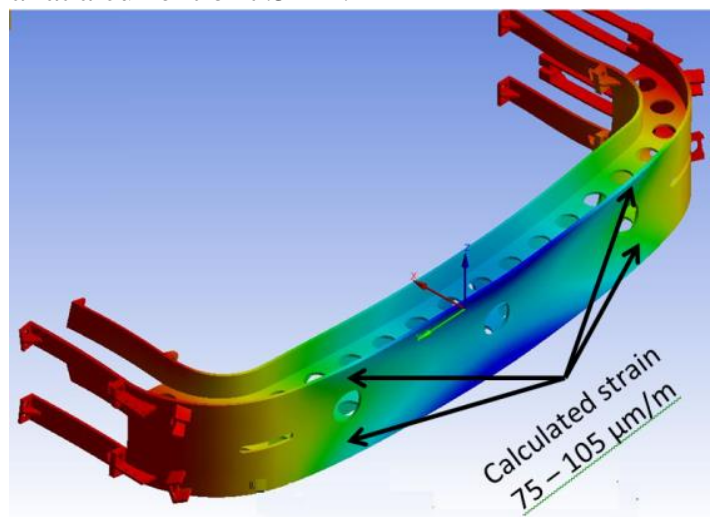

Fig. 10. Calculated strain on one half of the coil support structure with the 4 strain gauges indicated. 
The magnet is supported by eight Invar tie-rods that account for about $60 \%$ of the total thermal load of $5 \mathrm{~W}$ [3]. A strain of 20 to $155 \mu \mathrm{m} / \mathrm{m}$ was measured on the rods and no sign of degradation has been observed during the 20000 cycles, see Fig. 11.

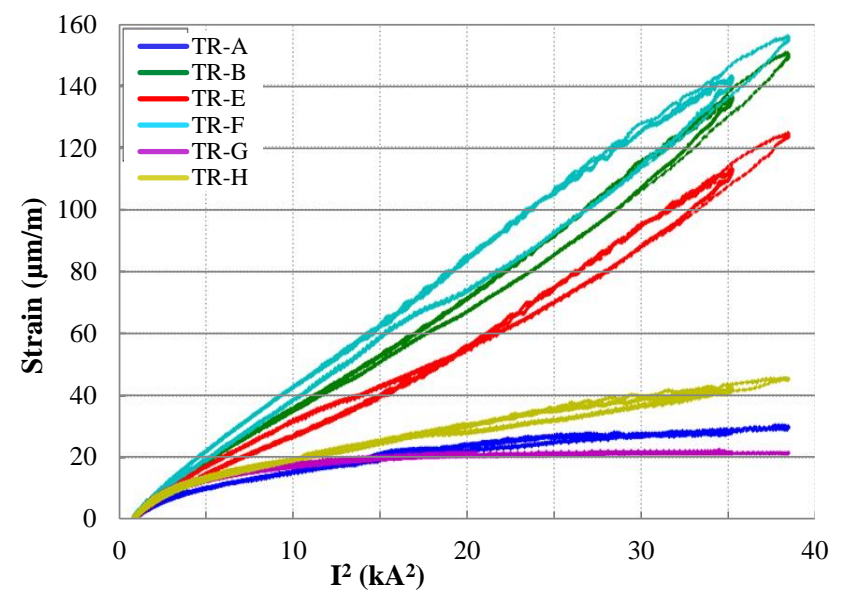

Fig. 11. Strain measurement during the magnet cycling as function of $I^{2}$ for six tie rods.

\section{MAGNETIC FIELD AND PERFORMANCE}

The magnetic field in the bore is mainly determined by the shape of the iron yoke. The maximum magnetic field in the conductor is only $40 \%$ of the peak field in the center of the magnets bore. The calculated field profile on the conductor is shown in figure 12 .

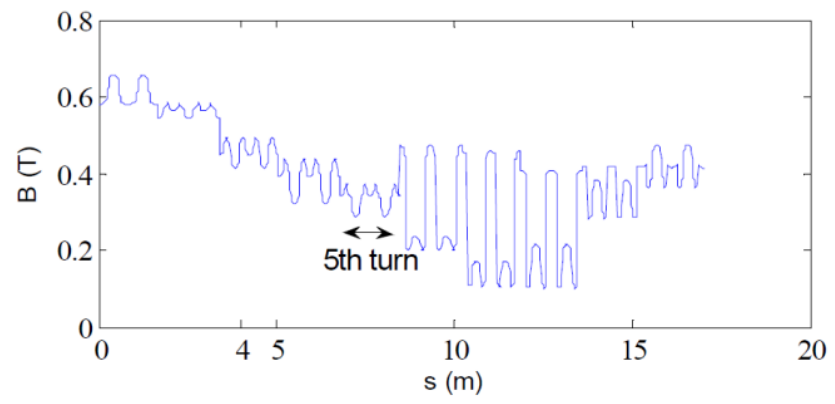

Fig. 12. Calculated field on the conductor at nominal current.

A longitudinal scan with a $700 \mathrm{~mm}$ long rotating pickup coil was carried out to measure the dipole field in the center of the bore [7], see Fig. 13.

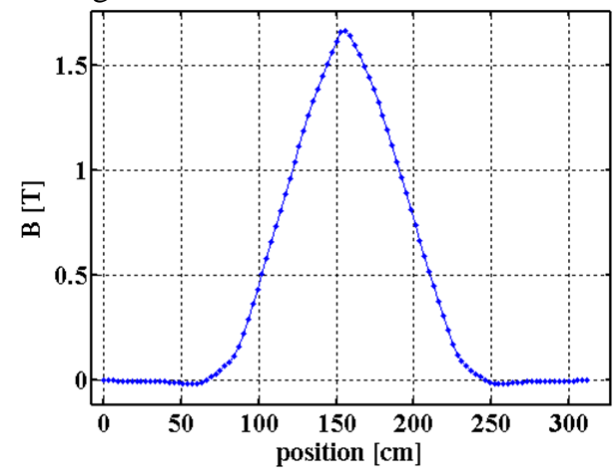

Fig. 13. Measured field profile in the bore of the magnet with the $700 \mathrm{~mm}$ long pickup coil.
By means of de-convolution the measured field profile was reconstructed to the magnetic field profile in the center of the bore with an accuracy of $3 \%$. The resulting field profile, with a maximum field of $1.73 \mathrm{~T}$ is compared in Fig. 14 with the calculations performed with the Roxie code.

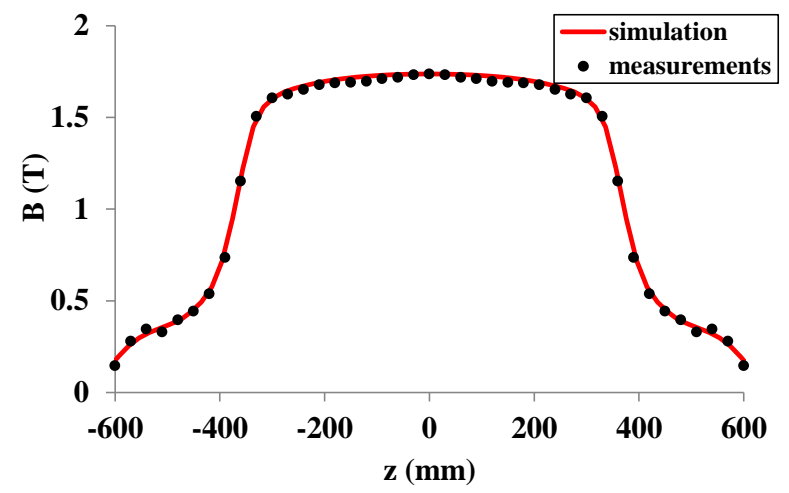

Fig. 14. Measured magnetic field profile in the center of the magnet bore as a function of the position in the magnet.

The multipole errors were measured at the reference radius of $17 \mathrm{~mm}$ and at a current of $3 \mathrm{kA}$, see table 1 . For this iron dominated magnet the yoke shape has more influence on the field errors than the cable position. The magnet is not optimized for field errors and therefore they are relatively high, specifically for $b_{3}$ with a value of 7.5 units.

TABLE I

MULTIPOLE FIELD ERRORS IN $10^{-4}$ UNITS

\begin{tabular}{lll}
$n$ & \multicolumn{1}{c}{$b_{n}$} & \multicolumn{1}{c}{$a_{n}$} \\
\hline 2 & 1.47 & 0.10 \\
3 & 7.5 & -0.02 \\
4 & 0.00 & 0.00 \\
5 & 0.03 & 0.00 \\
\hline \hline
\end{tabular}

\section{CONCLUDING REMARKS}

With the successful testing of the prototype the R\&D phase goals have been largely achieved. A number of concepts and techniques have been successful applied: the cold SC coil in warm iron, the low $\mathrm{AC}$ loss internally cooled cable, the vacuum impregnated coil in a strong coil casing, constant length tie-rods, de-mountable low-resistance joints, co-wound voltage taps for compensation of inductive voltages, and CCS thermometry.

After 4 training quenches $7.5 \mathrm{kA}$, the short sample limit has always been reached to currents up to $7.5 \mathrm{kA}$, which gives $50 \%$ higher Lorentz forces than nominal. In addition magnet stability during cycling has proven to be excellent, even at a temperature of $6.5 \mathrm{~K}, 0.5 \mathrm{~K}$ from the short sample limit.

The good overall performance of this first prototype has shown that the magnet has the potential of being applied in the CERN accelerator complex.

\section{REFERENCES}

[1] L. Bottura, A. Bonasia, F. Borgnolutti, W. Gaertner, S. Le Naour, L. Oberli, G. Peiro, D. Richter, T. Salmi, G. Sikler, G. Willering, "Strand and cable R\&D for fast cycled magnets at CERN", IEEE Trans. Appl. Superconductivity, Vol 21, 3, pp 2354-2358, 2011 
[2] F. Borgnolutti, L. Bottura, A. Nijhuis, C. Zhou, B. Liu, Y. Miyoshi, H. Krooshoop, D. Richter, "AC loss in the superconducting cables of the CERN fast cycled magnet prototype", Ph. Proc., 36, pp 1087, 2012

[3] V. Datskov et al., "Precise thermometry for next generation LHC superconducting magnets", MT-23 conference, Boston, July 2013

[4] F. Borgnolutti, B. Auchmann, L. Bottura, F. Carra, G. Foffano, J.M. Gomes De Faria, O. Kalulouguine, G. Kirby, C. Lopez, and D. Tomassini, "Construction of the CERN fast cycled superconducting dipole magnet prototype", IEEE Trans. Appl. Superconductivity, Vol 22, No 3, June 2012

[5] L. Bottura, "A practical fit for the critical surface of NbTi", IEEE Trans. Appl. Supercond. Vol 10, No 1, March 2000

[6] M. Guinchard, "Mechanical characterisation of the Fast Cycle Magnet (FCM): Displacement and strain measurements", Mechanical test report, EDMS 1173289, CERN, Geneva, Switzerland, 2012

[7] L. Fiscarelli, S. Russenschuck, "Magnetic measurement of the fast cycled superconducting magnet (FCM)", MSC/MM measurement note 2012-2, CERN, Geneva, Switzerland, 2012 